pated, and its advance must be sought in the application of steam power. It will be generally admitted that our existing home-difficulties are in no way due to defective apparatus.

Capt. Temple, in writing on "Seal Fisheries," adopts the wise course of holding himself responsible only for those of which he has had actual experience, leaving a hiatus, filled in during discussion by Mr. Martin and others. Devoting but little attention to the legal aspect of the industry, which we venture to say stands, with us, sorely in need of reform, the author seems more hopeful than the world at large of the chances of the chase. The body of the paper sets forth the modus operandi of the unenviable life of the sealer, whose lot entails great hardship, of ten rendered none the less buoyant for an excess of oil, nor the less happy under a "truck system." More might have been said with regard to this industry.

Turning now to other countries, we have most prominent a highly important paper on "The Fishery Industries of the United States," by Prof. Brown Goode. Some idea of its contents will be formed when we say that it fully bears out the impression made by the magnificent exhibits of that country, to study which delegates have even been sent over from other lands. The paper is a mine of useful information, and the refreshing speeches which have fallen from its author during the Conference meetings have shown how much remains untapped. The accounts given of refrigerator-cars, special oyster-trains, of the utilisation of waste, and the wellknown potting system on the economic side; of floating hatcheries, of the artificial propagation of fish (twentyseven.species), and other practical topics; and on the administrative side, of the amount of liberty allowed in matters where a more jealous State might interfere, surely point to a common moral. The history of the Menhaden fishery cannot fail to strike all readers as an example of what can be done by persevering in a "new departure," and it is important to note that the system of management and insurance of the boats composing the American fishing fleets is such as to give every impetus to the work by arousing the best interests of the men, at the same time insuring those of the capitalist. The statements advanced in both this and a paper on the Canadian fisheries, by Mr. L. Z. Joneas, are based upon deductions from a most perfect system of registration. The status of the latter country-jealous of its reputation-in fishing matters is everywhere recognised, but even it has to record the failure of attempts to artificially cure the codthe staple fish of its trade-and the writer deplores, for good reasons, the want of export traders in this the leading enterprise of its fishing population. The herring and mackerel fisheries are also dealt with, and it is reassuring to us to read that for the regulation of its lobster fisheries, of ten years' standing, Government measures are still being taken. The written account of the seal fishery conveys a good notion of its importance and a far better one of its technique than do certain sanguinary models exbibited in the Newfoundland section. The method of working a steam service on a wage system (in connection with their Great Lake fisheries) is worthy of attention.

Coming nearer home, Prof. Hubrecht, on behalf of the Dutch Government, tenders some very valuable observations upon the "Oyster Culture and Fisheries in the Netherlands." Upon the present state of our oysterbeds no comment is needed, any more than upon the fruitless efforts on the part of private individuals to establish new fisheries in our own waters. The experimental evidence-the result of observations still going onbrought forward by the author is of the highest importance; statistics favourable to artificial culture are given, the period of sexual maturation has been determined, and these and other similar facts ascertained all point to the conclusion drawn, viz. that "a close time may be of service, but that the great thing appears to be to leave a fair portion of the oysters on or around a natural bed wholly undisturbed for a series of consecutive years." This fact, discovered by chance in the Netherlands, embodies the sense of a statement made by Prof. Huxley in the matter in his opening address. It is noteworthy that the purely scientific biological and physico-chemical aspects of this question have received their full share of attention.

The main question bearing upon Mr. C. Harding's paper on "Mollusks" is that of bait. As the matter stands, action would be premature, until it can be shown that other forms of bait than those now in use are of no avail. It is well known that, on the one hand, fishermen are often compelled to stay on shore for want of bait, and on the other, it must be remembered that they are as conservative in this matter as in any which concerns them; but the fact that under like circumstances the Lofoden Islanders carry on a brisk catch by aid of the "gill-net," must not be overlooked.

(To be continued.)

\section{THE PARIS OBSERVATORY EQUATORIAL}

$T \mathrm{HE}$ accompanying illustration represents the remarkable apparatus recently set up in the Observatory of Paris, to which we have before called attention, the ingenious construction of which is due to M. Lœwy, sub-director of that establishment. Begun under the administration of M. Delaunay, interrupted during the war, thanks to a new act of munificence on the part of M. Bischoffsheim, it has now been finished.

To answer the requirements of modern astronomy equatorials are necessarily gigantic. Like the guns of modern warfare, each new apparatus is constructed on a larger scale than that of its predecessors, though it is not for purposes of destruction that they are aimed at the celestial bodies.

The advantages of the new equatorial are (I) that it measures great angular distances; (2) that it enables observations to be made with comparative ease and rapidity. Seated on a fixed chair apart from the support of the instrument, the astronomer is as if placed before his writing-table. The instrument obeys him, not he the instrument.

The new telescope is bent at right angles, one part directed in a line with the axis of the eartb, and capable of turning round itself ; the other perpendicular to it, and therefore moving in the plane of the equator. At the extremity of the latter is a mirror, and at the elbow of the telescope, in the interior, another mirror, both forming with the axis an angle of $45^{\circ}$. These mirrors are intended to reflect to each other, and finally to the observer seated with his eye at the eyepiece, the image of the star which is the object of observation.

The loss of light from successive reflections is hartly perceptible. The deformation which the images might suffer from the use of mirrors of insufficient thickness bas been guarded against. In its optical qualities, too, the new equatorial is not surpassed by any telescope in the Observatory. Two advantages have thus been securedthe power of measuring great angular distances, and that of exploring the entire heavens, the observer regulating the apparatus himself, and not needing to shift bis position.

Another benefit resulting from these happy arrange ments must also be mentioned-the abolition of the Observatory with a heavy, urgainly, and expensive dome, and the substitution of one of much smaller compass and of much simpler construction. It consists of a movable part covering the object-glass end, and of a fixed part appropriated to the observer. When prozeeding to make observations the

$$
\text { I Frum Lic Nature. }
$$




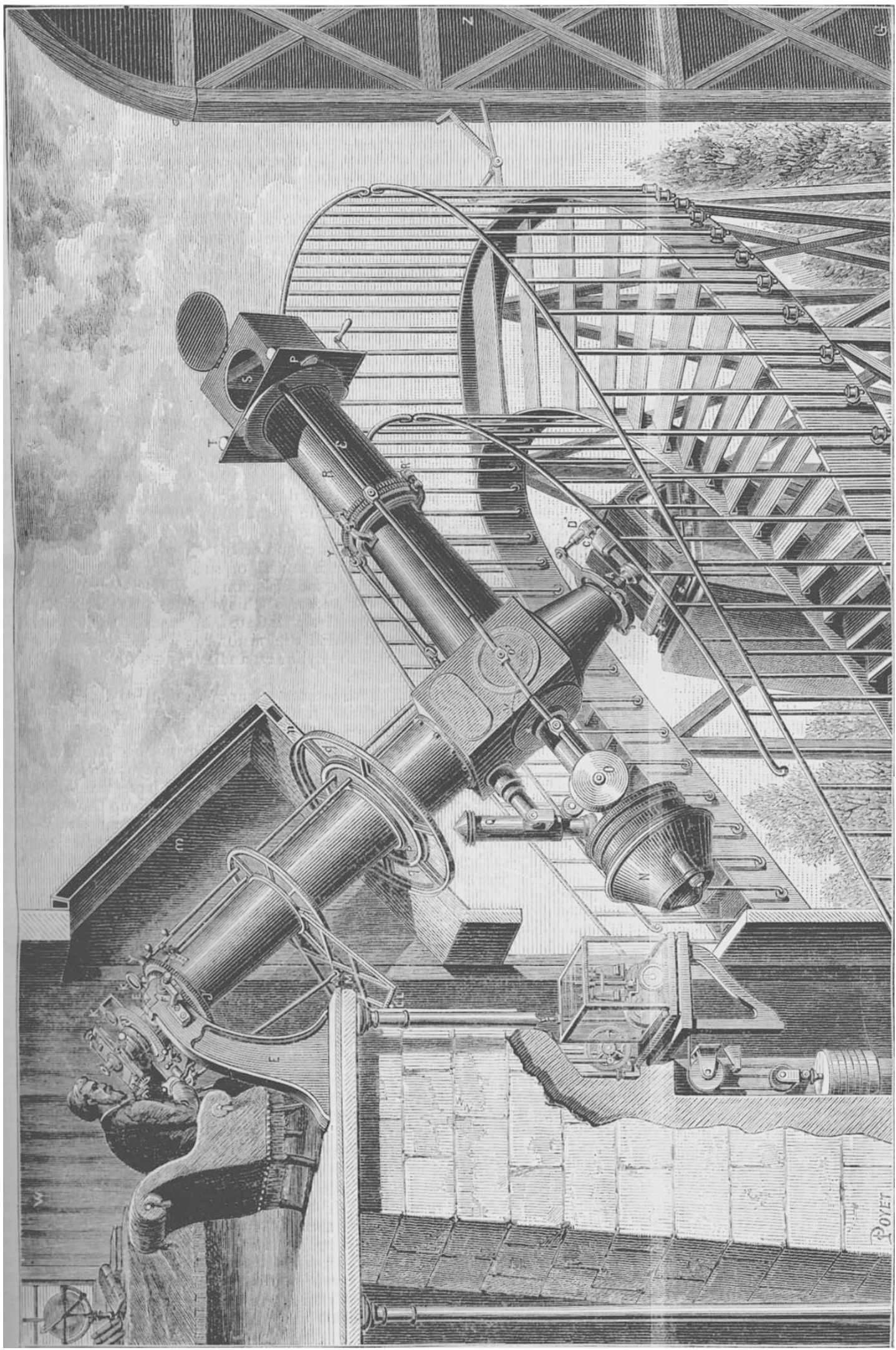


observer draws away the movable part, which readily rolls on a railway. The extremity of the teles zope bearing the mirror of the objective is thus left uncovered, while the astronomer, ensconced in his fixed part as in his own room, and sheltered from all inclemencies of weather, stidies the infinitely great in conditions as comfortable as those of the naturalist w'xo examine; under his microscope the infinitely little.

Seeing it is but just that those who bear the burden should also enjoy the honour, we again state that the optical part of this instrument has been executed by the Brothers Henry, and the mechanical part by MM. Eichens and Gauthier.

\section{THE INSTITUTION OF MECHANICAL ENGINEERS}

THE Institution of Mechanical Engineers have held their autumn meeting this year in Birmingham -a town which for many years was the headquarters of the Society. The returning to their former seat was specially opportune, because the first paper on the list related to one of the greatest of Birmingham worthie;, viz. James Watt. The title of the paper was "On the Inventions of James Watt, and his Models preserved at South Kensingand Handsworth." The author is Mr. Ed war $1 \mathrm{~A}$. Cowper, who, frum his long connection with en rineering both personally and through his futher and uncle, is perhaps as well fitte $d$ as any $m$ in in England to trace out the course of Watt's inventions. This he $\mathrm{h}$ is endeavoured to do, using as his main guide the numerous model s preserved partly at the South Kensington Museum, partly at the Patent Office Museum, and partly at James Watt's house at Hands sorth in Birmingham. Some of the models at South Kensinjton were in danger of falling altogether to pieces from dry rot an 1 decay, but o wing to the exertions o? Mr. Sandham, the curator of this department, they have, as far as possible, been rep iired; whilst, in addition, a complete set of photographs has been taken, whi h. even if the molels themselve; should cease to exist, would preserve their appearance and construction to future ages.

The sequance of James Watt's inventions with regard to the steam engine is stated at the end of Mr. Cowper's pıper as follows :-

Firstly, in 1769 he made an invention (the separate contenser) which was praztically an improvement on the Newcomen enrine, the effect of which was to work pum ping engines more economically and quickly.

Secondly, in $178 \mathrm{r}$ he produced rotative power for driving factories, obtaining it in a manner by having a heavy bulance weight to act one way whilst the steam acted the other way; however, the obtaining rotative motion by steam was an enorm ous advantage, far greater in its effect, in the author's opinion, than the improvement in the pu nping engine.

Thirdly, the crowning invention of 1782 made the steam engine the one uieful motive power, by making it double-actins and fit to drive cotton mills, flour mills, and all other machinery requiring rezular rotative motion.

These various stages are illustrated by the models above mentioned. It is indeed doubtful whether there exists at present any model embodying the first idea of the separate condenser; but there is a most interesting model at South Kensington showing the condensation of steam in a separate surface condenser, composed of a large number of vertical tube; and provided with an air pump. This form of contenser, which in many cases, such as marine engines, has superseded all others, is thus proved to have been invented by James Watt, and not only invented, but brought to a high degree of perfection. The arrangements in this molel, according to Mr. Cowper (than whom there can be no better authority), are in points equal to the best modern examples of surface condensation.

The only model actu ally exhibited was an engine of the character of Watt's patent of I77I. It is single acting, and has an open-topped cylinder, air pump, and condenser. There is a heavy bob on the connecting rod, which is used to help the piston up, while the vacuum formed below it causes it to descend on the return stroke, thus obtaining rotative motion. This engine, however, has a crank, and it is known that for many years Watt was afraid to use the crank in his engines, as it was supposed to be barred by another patent : it is true that his patent of I77 I shows a crank composed of a pin in a disk, but this is carefully termed "the poin" of attach. ment of the connecting rod." In practice, however, he used other methods, chiefly the well known sun and planet motion. Of this there are several different forms, which are illustrated by models at South Kensington. There is also a device consisting of a long rack or la 1der fixed to the end of the connecting rod and digging into the teeth of a spur wheel on the engine shaft; the rol being guided by means of rollers running in a guide plate, so as to keep it in gear throughout the revolution.

Turning now to the I 782 patent, we find what Watt describes as "the new improved en rine, the piston of which is pressed forcibly both up wards and downward; by the power of steam," that is to say, the en rine is no longer single-acting, but double-acting. Here the chain hitherto used between the piston-rod and beam is replaced by a parallel motion, and the engine takes very much the form which was still common for shop engines within recent years. A good model of sush an engine exists in the South Kensington Museum.

Some variations of this engine, probably made subjequeiatly, are also illustrated by models, such as the Bull engine, in whi sh the piston-rod passe.s out through the bottom of the cylinder, and takes holl of a beam placed lower down.

Still more interesting are Watt's prop ssals to ma'ze use of the expansion of stea $n$ for the saving of fuel; a diagram in one of his specifications shows that he fully understoot this action, and he gives several methols by which the load upon the piston may be varied so that when the pressure is least it shall have least wor'k to do. One of these is to mount a weight high up above the beam, which would be lifted when starting from either end of the stroke, and fall after passing the centre; this has been used even in recent times with good re sulcs. Several $\mathrm{m}$ : scellaneous inventions of high interes! are also described; one of these is the well-known invention of the steam indicator in probably its earliest and rudest form. Another is a counter for telling the revolutions of an engine, of which an actual specimen in good preservation remains in the Patent Office Museum.

There is also an arangement for obtaining rotary $\mathrm{m}$ )tion in opp ssite directions out of the same engine by means of two connecting rods starting from a cross-head at one end of the beam, but working opposite ways. Another model shows two hammers worked by a single engine, the one lifted from the belly like an ordinary forge hammer, and the othar by depressing the till like a tilt hammer. A yet more curious device is a semi-rotary engine, of which an unfinished model remains in the Watt Room at Heathfield Hall. Here there is a pi iton fixed in a radial line to the shaft, within a large disk or cylinder. Inside this cylinder, at one part, is a fixed support, against which the steam presses each way as it acts against the pist in, in either one direction or the other. The reciprocating shaft was made to act by a spur wheel on two racks attached to the pump rods. Watt also invented a very simple form of rotary engine, which, as Mr. Cowper states, has probably been reinvented at least fifty tim 2 s since 1782 , the year of his patent. 